\title{
Structure-Directing Role of Amines in the Ionothermal Synthesis
}

Lei Wang, , Yunpeng Xu, Ying Wei, Jicheng Duan, Aibing Chen, Bingchun Wang,

Huaijun Ma, Zhijian Tian, and Liwu Lin

\section{Supplementary Data}

\section{Characterizations}

Powder X-ray diffraction spectra were collected by using a Phillips X'Pert Pro $\mathrm{X}$-ray diffractometer with nickel-filtered $\mathrm{Cu} \mathrm{K} \alpha$ radiation $(\lambda=1.54 \AA)$ at $40 \mathrm{kV}$ and 40 $\mathrm{mA}$. The $2 \theta$ angles were scanned from $5^{\circ}$ to $55^{\circ}$ at a rate of $5^{\circ} \mathrm{min}^{-1}$. The sample morphology was examined by SEM (JEOL JSN-6460LV model). Proton and ${ }^{13} \mathrm{C}$ NMR spectra were recorded at $80^{\circ} \mathrm{C}$ on Bruker DRX-400 spectrometer at 400 and $100 \mathrm{MHz}$, respectively. The samples were hermetically sealed in 5-mm Pyrex tubes. For reference purposes, a sealed capillary containing $\mathrm{D}_{2} \mathrm{O}$ was placed inside each Pyrex tube. Thermogravimetric analysis (TG) was accomplished on a Perkin-Elmer Diamond analyzer at a rate of $10^{\circ} \mathrm{C} \mathrm{min}^{-1}$ under flowing air.

The typical SEM images of the three different aluminophosphate molecular sieves prepared in this study are shown in Figure 1.
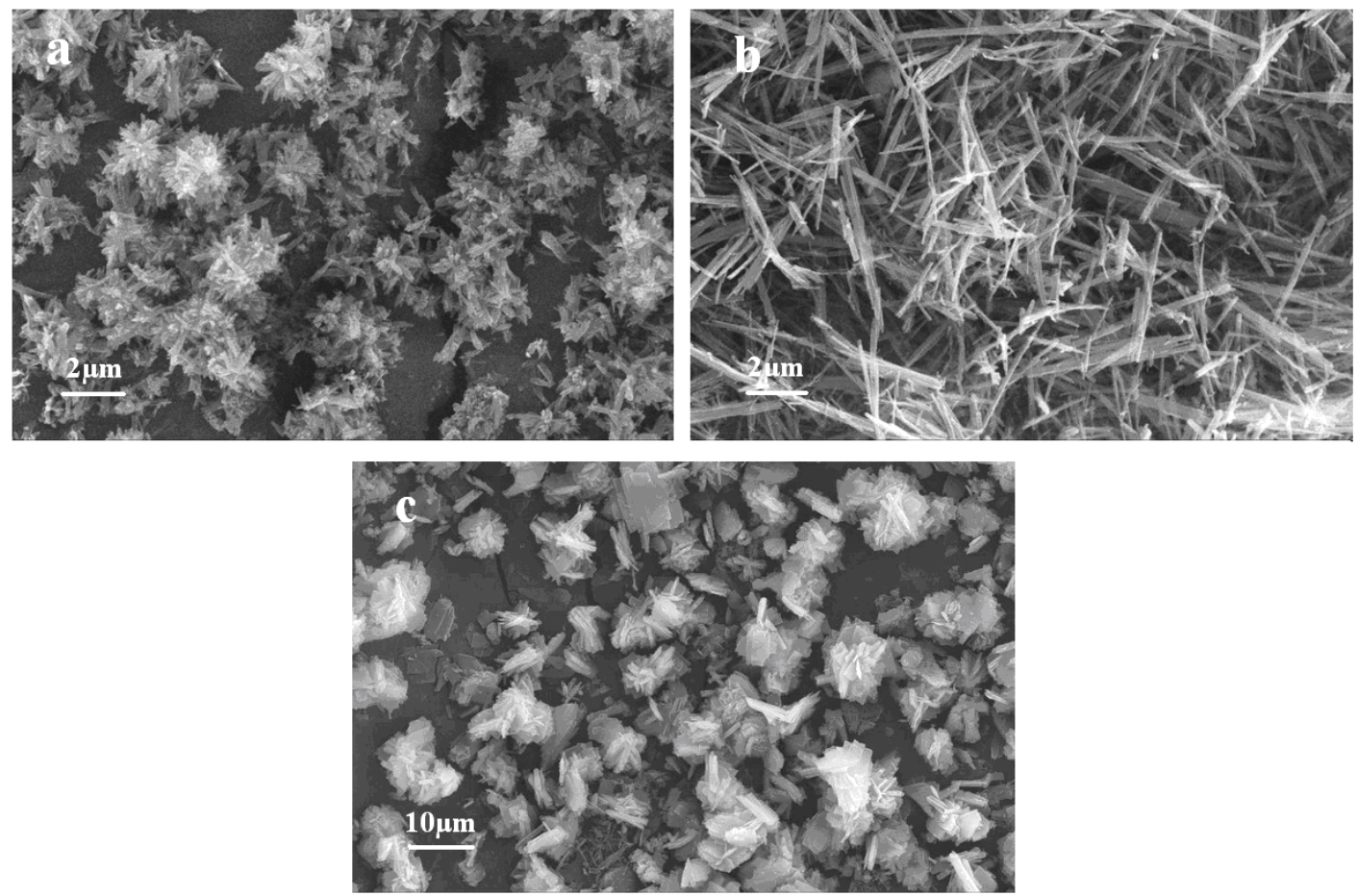

Figure 1. Typical SEM images of (a) $\mathrm{AlPO}_{4}-5$, (b) $\mathrm{AlPO}_{4}-11$, (c) $\mathrm{AlPO}_{4}-25$ prepared in the presence of n-DPA, the molar ratio of $[\mathrm{bmim}] \mathrm{Br} / \mathrm{n}-\mathrm{DPA}$ is 20 . 
The ${ }^{1} \mathrm{H}$ NMR spectra data of $[\mathrm{bmim}] \mathrm{Br}$, a mixture of $[\mathrm{bmim}] \mathrm{Br}$ and 1-methylimidazole (MIA), and a mixture of [bmim]Br and n-dipropylamine (n-DPA) are shown in Table 1.

Table $1 .{ }^{1} \mathrm{H}$ NMR spectral data (400 MHZ; $\delta / p p m$ Relative to $\mathrm{D}_{2} \mathrm{O} ; 80^{\circ} \mathrm{C}$ ) for $[\mathrm{bmim}] \mathrm{Br}$.

\begin{tabular}{lccccccccc} 
& & & & & & \\
\hline sample & $\mathrm{H}(2)$ & $\mathrm{H}(4)$ & $\mathrm{H}(5)$ & $\mathrm{H}(6)$ & $\mathrm{CH}_{3}$ & $\mathrm{H}(7)$ & $\mathrm{H}(8)$ & $\mathrm{H}(9)$ \\
\hline$[$ bmim $] \mathrm{Br}$ & 11.04 & 9.33 & 9.24 & 5.43 & 5.14 & 2.81 & 2.19 & 1.73 \\
[bmim] & 11.01 & 9.22 & 9.11 & 5.41 & 5.10 & 2.85 & 2.65 & 1.82 \\
{$[$ bmim $] \mathrm{Br}+\mathrm{MIA}^{\mathrm{a}}+\mathrm{n}-\mathrm{DPA}^{\mathrm{a}}$} & 10.79 & 9.17 & 9.07 & 5.42 & 5.11 & 2.83 & 2.23 & 1.77 \\
\hline
\end{tabular}

${ }^{\mathrm{a}}$ The molar ratio of [bmim]Br/amine is 2 .

The ${ }^{13} \mathrm{C}$ CP-MAS NMR spectra of the $\mathrm{AlPO}_{4}-5$ sample synthesized with the addition of n-DPA (corresponding to sample 5 in Table 1 of the text) are shown in Figure 2, together with the ${ }^{13} \mathrm{C}$ NMR spectrum of [bmim] $\mathrm{Br}$ and n-DPA. These spectra allowed us to assign all carbon atoms.

When n-DPA and [bmim] $\mathrm{Br}$ are occluded in the channels of the molecular sieves, the NMR spectrum is not markedly changed from that of the solution. Lines are considerably broadened, but most of the peaks possess approximately the same chemical shift value. As can be seen, three lines at 139.7, 126.1 and $123.9 \mathrm{ppm}$, corresponding to the three non-equivalent carbon atoms of the imidazolium ring, overlap into two broadened peaks of the solid state NMR spectra. It confirms that [bmim] $\mathrm{Br}$ is occluded inside the final structure of ionothermally synthesized $\mathrm{AlPO}_{4}-5$. However, peaks at 50.2, 21.1 and $13.2 \mathrm{ppm}$ assigned to the three carbon atoms of the $\left(\mathrm{NCH}_{2} \mathrm{CH}_{2} \mathrm{CH}_{3}\right)$ propyl chains of n-DPA, can not be resolved from the carbon atoms of $\left(\mathrm{NCH}_{2} \mathrm{CH}_{2} \mathrm{CH}_{2} \mathrm{CH}_{3}\right)$ chain of [bmim]Br in solid state NMR spectrum.

Moreover, the peaks of the NMR spectra of the AlPOs sample synthesized without the addition of amine (not shown here) possess the same chemical shift value as that of the $\mathrm{AlPO}_{4}-5$ sample shown in Figure 2. However, the intensities of the peaks of the AlPOs sample synthesized without the addition of amine are much lower than that of the $\mathrm{AlPO}_{4}-5$ sample synthesized with the addition of n-DPA.

TG-DTG profiles of the $\mathrm{AlPO}_{4}-5$ sample synthesized with the addition of n-DPA (corresponding to sample 5 in Table 1 of the text) and the mixture of $\mathrm{AlPO}_{4}-5$ and $\mathrm{AlPO}_{4}-11$ sample synthesized without the addition of amine(corresponding to sample 1 in Table 1 of the text) are shown in Figure 3. Two different regions can be distinguished: one around $100^{\circ} \mathrm{C}$, corresponding to the removal of physically adsorbed water, and the other one in the $250-450^{\circ} \mathrm{C}$ temperature range, corresponding to the removal of the template. However, the weight losses of the stage from 250 to $450^{\circ} \mathrm{C}$ of the two samples are different, i.e. $8.65 \%$ in Figure $3 \mathrm{a}$ and $5.79 \%$ in Figure $3 \mathrm{~b}$. This suggests that the amount of the organic template in the pores of AlPOs synthesized with the addition of amine may be higher than that of AlPOs synthesized without the addition of amine. 

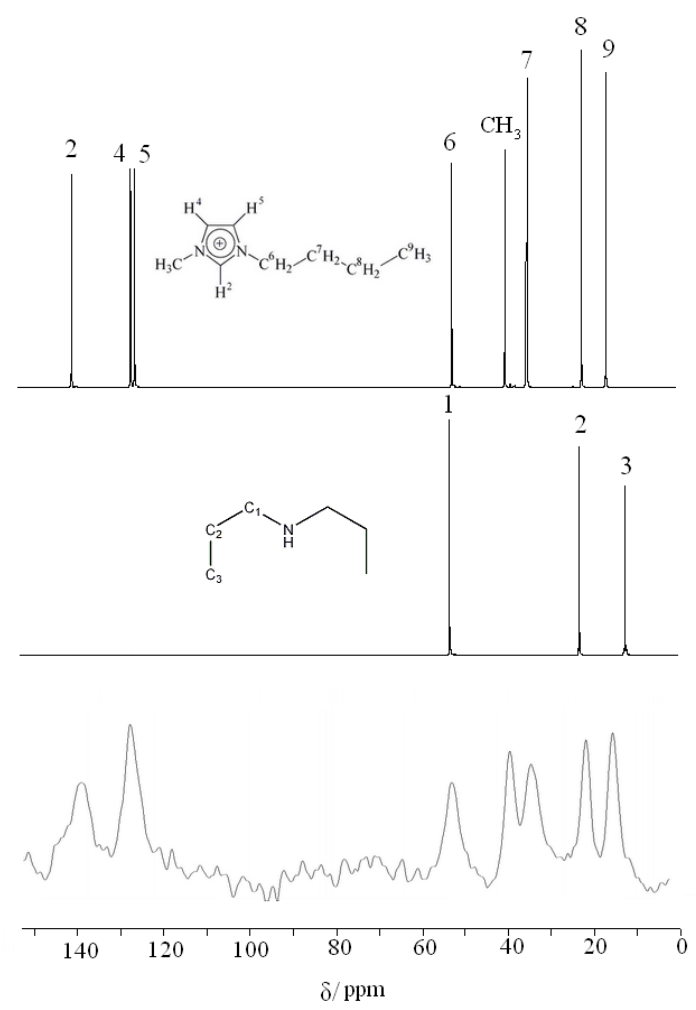

Figure 2. ${ }^{13} \mathrm{C}$ NMR spectra of (bottom to top): $\mathrm{AlPO}_{4}-5$ synthesized with the addition of n-DPA (corresponding to sample 5 in Table 1 of the text); n-DPA; and [bmim]Br.
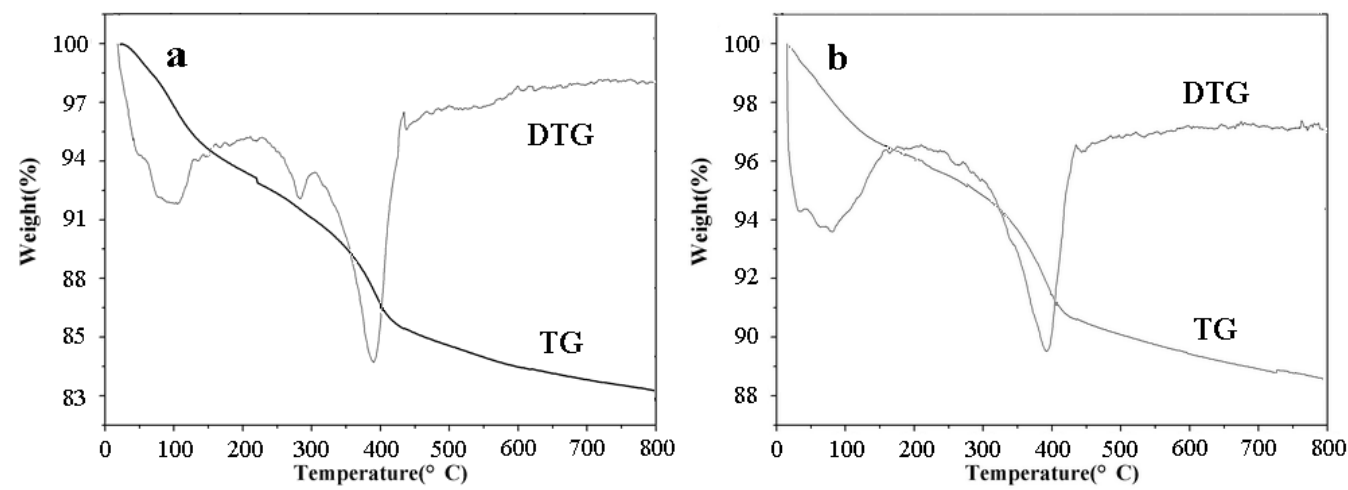

Figure 3. TG-DTG profiles of a) $\mathrm{AlPO}_{4}-5$ sample synthesized with the addition of $n$-DPA (corresponding to sample 5 in Table 1 of the text), b) mixture of $\mathrm{AlPO}_{4}-5$ and $\mathrm{AlPO}_{4}-11$ sample synthesized without the addition of amine (corresponding to sample 1 in Table 1 of the text). 